\title{
An Editor's Opinion on the Ethics of Open Access
}

\author{
Cynthia T. Fowler, Co-Editor of Ethnobiology Letters and Secretary of the Society of Ethnobiology
}

Author address: Wofford College, Spartanburg, South Carolina 29303

fowlerct@wofford.edu

Received: December 13, 2013

Volume 5:1-3

Published: January 13, 2014

(C) 2014 Society of Ethnobiology

My approach to writing this editorial is to describe Ethnobiology Letters's (EBL) open access model and to present it as one that is, in my opinion, highly ethical. Other authors (e.g., Beall 2013; Kolata 2013) have written about the ethical shortcomings of open access by criticizing publishers' use of academic covers to mask profit-seeking motives, overcharging authors or only revealing charges late in the publication process, shortchanging or eliminating peer review, enabling plagiarism, and other unscrupulous practices. Rather than furthering this track in what is a truly engaging dialogue, I follow an alternative trajectory here by offering EBL as a prototype for an ethical open access journal. My hope is not only that other publishers, editors, and authors will find a description of EBL's model useful, but also that this essay will alleviate doubts that some people might have (which the aforementioned dialogue, in part, may generate) about the worthiness of open access.

The Society of Ethnobiology Board of Trustees initiated EBL in May 2010 to expand its publishing portfolio into the realm of open access. Our Society's Board took that bold step because our flagship journal, the Lournal of Etbnobiology, was considering discontinuing or dramatically shortening its book review section due to the costs of traditional printbased publishing. This step was also taken because open access represents a financially sustainable venue, thanks to the support of our growing membership base (in 2014 have over 500 members). The purpose of this editorial for the fifth volume of EBL is to highlight several important issues related to the ethics of open access from the point of view of an editor of an up-and-coming journal and a board member of a 40-year-old-and-still-maturing professional organization.

Open access is moral primarily, I believe, since it places high quality scholarly information into anyone's hands at no cost and from any location where the Internet is available. Secondarily, I believe that open access is an honorable endeavor ecologically since online publication requires no conventional resources (paper, ink, fuel) to print and distribute content. EBL is committed to promoting the agendas of social justice and environmental sustainability while simultaneously delivering excellent scholarship to the world.

Financial support from the Society of Ethnobiology enables EBL's purist stance to open access. I use the term "purist" not with a sanctimonious attitude, but instead to recognize that we are a viable journal (and thus do not charge authors or readers) due almost completely to support from our organizational home, and that other open access publications may need to exact fees from authors or readers in order to be financially sustainable. Open access journals that include author-pay, reader-pay, membership-pay, or database subscriber-pay mechanisms in their models can still-although not completely free-be ethical. At the same time, numerous scholarly communities are developing low-cost, ethical, innovative business models (Esposito 2008). At EBL, monies collected from membership dues, subscription income from the Journal of Ethnobiology, interest from investments, and proceeds from conferences paid our web manager, Takahashi Design, to create and maintain our web presence for the first four years and coordinate our migration to our new platform on Public Knowledge Project's Open Journal Systems's open source software. The Society of Ethnobiology also covers all fees for membership in the CrossRef consortium of publishers which enables us to assign DOIs to articles and, hopefully in the future, to use CrossCheck to ensure originality. As editors, we-Cissy Fowler (Wofford College), Steve Wolverton (University of North Texas), and James R. Welch (National School of Public Health in Rio de Janeiro) in addition to a diverse board of associate editors-donate our time to EBL, which we are fortunate enough to be able to do 
because academic institutions pay our salaries. We have also received financial support from Wofford College to retain students as editorial assistants. Above all, EBL is viable because the Journal of Ethnobiology's audience pays subscription dues and members of the Society of Ethnobiology pay nominal dues, which range from $\$ 15 /$ year for online access to the Journal of Ethnobiology for students, to $\$ 20 /$ year for retirees, $\$ 25 /$ year for professionals, and $\$ 150$ for institutions. Thanks to this generous support, publishing in EBL remains free for authors and readers. If you like EBL, then become a member, buy someone a gift membership, and help us grow our community of ethnobiologists.

Providing open access to scholarly articles about relations between humans and biota does not necessarily mean people living in rural or underdeveloped regions, who are sometimes subjects of the studies we publish, will get online, search for or even stumble upon our modest journal, read our research, absorb our reports, share the information with friends and family, and use the knowledge contained in our virtual pages as they move through their worlds. Yet, the potential for greater fairness, for greater information equality helped us arrive at Volume 5 and rapidly drives us into our future.

Can you see the potential of open access publishing and of EBL? Can you afford to write without compensation while we publish for no cost? Contribute by sending your writing to us or volunteer to peer review articles in order to share your knowledge with people all over the world who are already reading articles for free. Perhaps those people who you could/would reach through EBL's open access content are the subjects or descendants of the subjects of your research. The goal that writers' subjects become members of their audiences becomes even more realistic with open access publishing. What do you achieve, morally, by sharing your research-electronically and potentially immediately-with the people who appear in your writings and their descendants? Among other repercussions, your accountability for accuracy may increase and your obligation to protect interlocutors may gain greater immediacy. Ethnobiologists ought to consider how the lives of their subjects and/or their subjects' descendants will change when they read about themselves, or see photos and videos of themselves, as well as how knowing the outcomes of ethnobiological research will affect future fieldwork endeavors in the subjects' societies. 'Economic empowerment" (Das 2008:1), "enhance[ed] educational and research opportunities" (Sreenivasan 2008:vii), and "saving researchers in [developing] countries immense expenses and time with their own experiments" (Herb 2010) are potential outcomes of open access, although some authors doubt that open access will have a "levelling and democracy-boosting effect' (Herb 2010). Perhaps you have witnessed the effects, or the lack of effects, of increased accessibility for people who previously were not able to locate scholarly publications, and could thus write an article for EBL about the implications of projects like ours.

Publishing ethnobiological essays in an open access journal may better serve the inner circle of scholars (Esposito 2010) who are deeply committed to ethnobiology by providing them with a virtual location for reading timely, relevant reports because of the vetting services that our editorial team and crew of reviewers performs. Idealistically, open access publishing also expands our disciplinary community by enabling more people in more parts of the world to read about ethnobiology's methods, theories, and research results, but proof of concept is not yet available to us. If our community does become more spatially and cultural dispersed, it might come to include more people who are, or who bear certain similarities with, ethnobiology's interlocutors, including indigenous persons and subalterns, although we recognize that many rural people's ability to consume scholarly information is still limited by the inaccessibility of computers and Internet connections.

EBL supports authors and readers by advocating for digital inclusion. While EBL advocates for digital inclusion on behalf of information impoverished people including our own interlocutors, we also support authors' need to maximize their scientific capital (Bourdieu 2002). I believe that journals who begin their lives as open access (like EBL) as well as journals who convert from restricted access will eventually, if they have not already, achieve high impact factors and therefore afford merit to authors accustomed to publishing in restricted access journals with high impact factors. Moreover, as publishing in open access gains moral status with respect to traditional restricted venues, authors may perceive it has additional benefits.

In this editorial, I have revealed some details about our journal's origins and funding as well as described my moral viewpoint. Mine is a post-print 
egalitarian ethos. "Academics need to do some soul searching," says Peter Ludlow (2013) referring to our allegiance to conventional systems for achieving merit by publishing in flagship journals because these tend to be restricted access titles. When the Society of Ethnobiology's leadership did some soul searching, we found that we agree with Aaron Schwartz who, in his Gorilla Open Access Manifesto, said, "You have a duty to share [the banquet of knowledge] with the rest of the world" (Schwartz cited in Ludlow 2013).

The Society of Ethnobiology is one among many publishers (see OASPA's list of publishers) who provide sustenance for the feast. Likewise, EBL is one among many reputable open access journals (see a list of 9804 at the Directory of Open Access Journals), including standout journals such as PeerJ and eLife, and exemplary repositories such as Mana'o, that uphold scholarly values by completing peer review to ensure that authors use valid methods for collecting information, analyzing data, and arriving at conclusions; who follow ethical practices with regard to their research collaborators; and who abide by additional guidelines established in, for example, the Data Management for Global Change Research Policy Statement from 1991, the Berlin Declaration from 2003, and the Tasman Declaration from 2013, and by organizations such as the Public Library of Science, the Compact for Open-Access Publishing Equity, the Open Access Scholarly Publishers Association, the Open Knowledge Foundation, and UNESCO. Along with these like-minded organizations and their editorial staffs, our team of editors, associate editors, and editorial assistants at EBL are participating in a larger movement that aligns with the belief that published scholarly knowledge should be everyone's privilege.

\section{References Cited}

Beall, J. 2013. Bourdieu, Pierre. 2002. Homo academicus. Suhrkamp, Frankfurt am Main.

Beall, J. 2013. Unethical Practices in Scholarly, OpenAccess Publishing. Journal of Information Ethics 22
(1):11-20.

Das, Anup Kumar. 2008. Open Access to Knowledge and Information: Scholarly Literature and Digital Access Initiatives-The South Asian Scenario. UNESCO, New Delhi. Available at: http:// portal.unesco.org/ci/en/ files/26393/12075628443open access book en.pdf Lopen access book en.pdf. Accessed on December 31, 2013.

Esposito, Joseph J. 2008. Open Access 2.0: Access to Scholarly Publications Moves to a New Phase. Journal of Electronic Publishing 11(2). Doi: http:// dx.doi.org/10.3998/3336451.0011.203.

Herb, Ulrich. 2010. Sociological Implications of Scientific Publishing: Open Access, Science, Society, Democracy, and the Digital Divide. First Monday 15(2). Doi: 10.5210/fmv15i2.2599.

Ludlow, Peter. 2013. Aaron Schwartz was Right. The Chronicle Review February 25, 2013. Available at: https://chronicle.com/article/Aaron-Swartz-WasRight/137425/. Accessed on December 24, 2013.

Kolata, Gina. 2013. Scientific Articles Accepted (Personal Checks, Too). New York Times April 7, 2013. Available at: $\underline{\text { http:// }}$ www.nytimes.com/2013/04/08/health/forscientists-an-exploding-world-of-pseudoacademia.html?pagewanted $=1 \& \mathrm{r}=0 \&$ smid $=\mathrm{fb}-$ share. Accessed on December 24, 2013.

Sreenivasan, K. R. 2008. Foreward. In Science Dissemination Using Open Access: A Compendium of Selected Literature on Open Access, edited by Enrique Canessa and Marco Zennaro, pp. vii-viii. The Abdus Salam Center for Theoretical Physics, Trieste, Italy. Available at: http://sdu.ictp.it/openaccess/

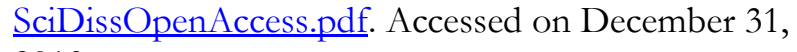
2013. 